\title{
Air pollution and trajectories of adolescent conduct problems: the roles of ethnicity and racism; evidence from the DASH longitudinal study
}

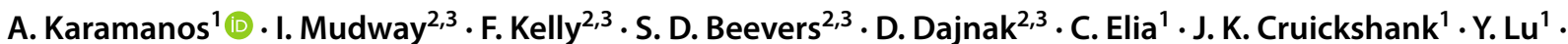

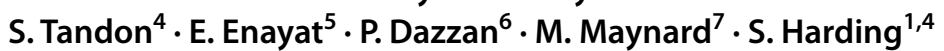

Received: 26 October 2020 / Accepted: 23 April 2021 / Published online: 30 April 2021

(C) The Author(s) 2021

\begin{abstract}
Purpose No known UK empirical research has investigated prospective associations between ambient air pollutants and conduct problems in adolescence. Ethnic minority children are disproportionately exposed to structural factors that could moderate any observed relationships. This prospective study examined whether exposure to $\mathrm{PM}_{2.5}$ and $\mathrm{NO}_{2}$ concentrations is associated with conduct problems in adolescence, and whether racism or ethnicity moderate such associations.

Methods Longitudinal associations between annual mean estimated $\mathrm{PM}_{2.5}$ and $\mathrm{NO}_{2}$ concentrations at the residential address and trajectories of conduct problems, and the potential influence of racism and ethnicity were examined school-based sample of 4775 participants (2002-2003 to 2005-2006) in London, using growth curve models.

Results Overall, in the fully adjusted model, exposure to lower concentrations of $\mathrm{PM}_{2.5}$ and $\mathrm{NO}_{2}$ was associated with a decrease in conduct problems during adolescence, while exposure to higher concentrations was associated with a flattened trajectory of conduct symptoms. Racism amplified the effect of $\mathrm{PM}_{2.5}(\beta=0.05$ (95\% CI 0.01 to $0.10, p<0.01)$ ) on adolescent trajectories of conduct problems over time. At higher concentrations of $\mathrm{PM}_{2.5}$, there was a divergence of trajectories of adolescent conduct problems between ethnic minority groups, with White British and Black Caribbean adolescents experiencing an increase in conduct problems over time.

Conclusion These findings suggest that the intersections between air pollution, ethnicity, and racism are important influences on the development of conduct problems in adolescence.
\end{abstract}

Keywords Air pollution $\cdot$ Conduct problems $\cdot$ Ethnicity $\cdot$ Racism $\cdot$ Cohort study

\section{Introduction}

Conduct problems refer to behaviours under the conductoppositional spectrum, including those that are defiant, antisocial, and/or potentially harmful to others such as lying, stealing, physical aggression, and rule-breaking [1],

A. Karamanos

alexis.1.karamanos@kcl.ac.uk

1 Department of Nutritional Sciences, School of Life Course Sciences, Faculty of Life Sciences \& Medicine, King's College London, 57 Waterloo Road, London SE1 8WA, UK

2 MRC Centre for Environment and Health, Imperial College London, London, UK

3 NIHR Health Protection Research Unit in Environmental Exposures and Health, Imperial College London, London, UK currently estimated to affect about one in twenty (6.2\%) of 11 to 16 years old. Literature shows that, in general, they are higher in childhood and decrease with time [2], while an increasing number of studies indicate that there may be subgroups of conduct behaviours that characterise the heterogeneity in developmental pathways of conduct problem

4 Department of Population Health Sciences, School of Population Health \& Environmental Sciences, Faculty of Life Sciences \& Medicine, King's College London, London, UK

5 Division of Psychiatry, Faculty of Brain Sciences, University College London, London, UK

6 Institute of Psychiatry, Psychology and Neuroscience, King's College London, London, UK

7 School of Clinical and Applied Sciences, Leeds Beckett University, London, UK 
behaviours across childhood and adolescence [3, 4]. They can be markers for co-morbid mental health problems [5], lower educational attainment [6], later criminality [7, 8], and adverse labour market experiences [9-11].

Growing evidence shows strong associations between structural factors such as racial discrimination and neighbourhood deprivation and conduct problems in childhood and adolescence [12-14]. Prior studies also show a link between conduct problems, and harsh discipline, poor parental monitoring, deviant peer affiliation, poverty, parental divorce, and parental psychopathology [15]. Air pollution, as a marker of environmental adversity, can affect adolescent mental health problems [16-20], via possible direct effects on brain neuroinflammation [21, 22], oxidative stress [23], microglial activation [24], cerebrovascular dysfunction, or changes in the blood-brain barrier [25]. Most studies are cross-sectional, with potential selection bias, and only one study modelled both ambient air pollution exposure and development of conduct problems over time [20]. In addition, there has been little attempt to consider gender or age effects, except for a US longitudinal study which reported no effect modification by age [20]. Psychosocial stress induced by experiences of racism may also contribute to differences in adolescent conduct problems either as a direct cause or via enhancing neuroimmune and hypersensitivity response to air pollution [26].

Some ethnic minority groups show better or similar levels of mental health overall in adolescence than White children and adolescents [27] which is not explained by socio-economic circumstances, family type, social support, or perceived parenting [28-30]. Indian, Black African, Pakistani, and Bangladeshi children report fewer behavioural problems, while mixed White/Black Caribbean children report more compared with White children. Ethnic minority adolescents are more likely to report racism, and reside in urban areas where ambient air pollution levels are higher [31]. These areas are also more income-deprived neighbourhoods where unemployment and crime rates are high and could disproportionately affect mental health outcomes [32-34]. No study exists which adequately accounts for intersections between ethnicity and air pollution or air pollution and racism, and their contribution to adolescent mental health. By exploiting the longitudinal design of the DASH study and data from 4775 adolescents aged 11-16 years, we explored the interrelationships between ambient air pollution, time, ethnicity, racism, and conduct problems. Figure 1 shows conceptual framework which guided the analyses of this study. We hypothesised that higher concentrations of fine particulate matter $\left(\mathrm{PM}_{2.5}\right)$ and nitrogen dioxide $\left(\mathrm{NO}_{2}\right)$ would be associated with: (i) a slower decrease of conduct problems over time, (ii) an increase in ethnic differences in conduct problems during adolescence, and (iii) racism would associate with an amplification any observed effect of air pollution on conduct problems.

\section{Methods}

\section{Design and sample}

The DASH longitudinal study is detailed elsewhere [35]. In brief, in 2002-2003, a total of 6631 students, aged 11-13 years, from 51 secondary schools in 10 London boroughs (highlighted in Supplementary Figure 1), took part at baseline. In 2005-2006, 4775 students took part in the follow-up survey. The overall response rate among those invited to take part in the follow-up was $88 \%$. Written informed consent was obtained from all participants.
Fig. 1 Conceptual framework of the association between residential air pollution and conduct problems

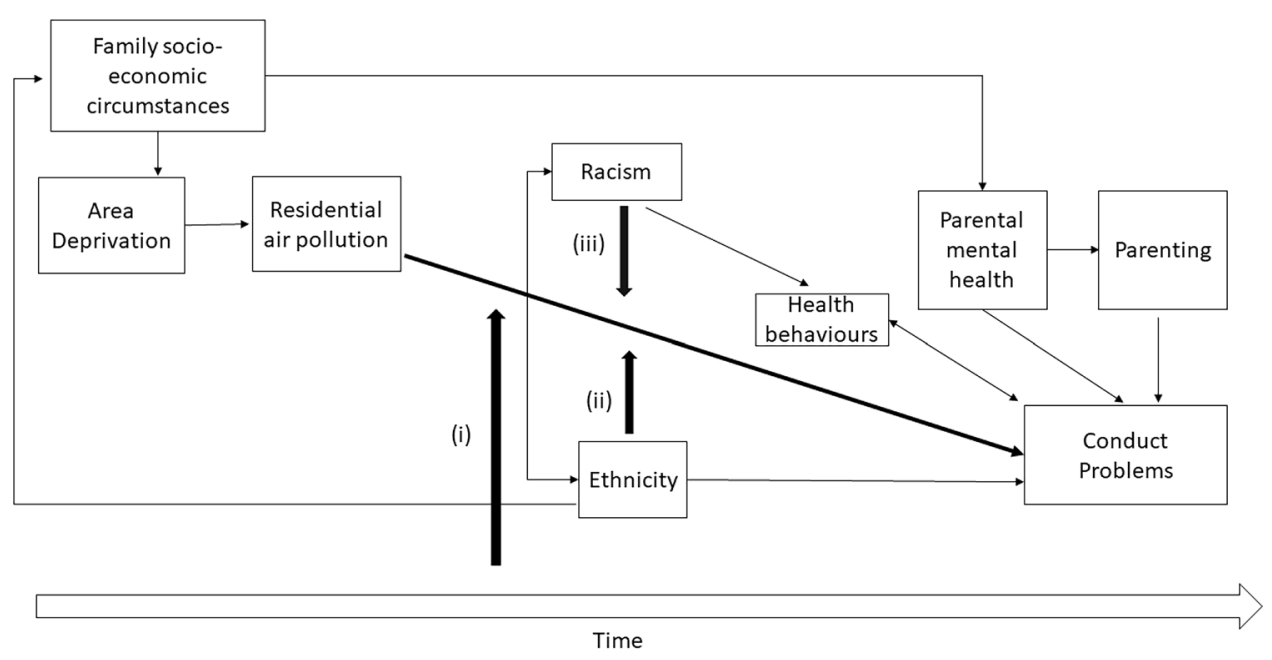




\section{Measures}

\section{Outcome: conduct problems}

Conduct problems in adolescence were measured by the conduct problems sub-scale within the self-reported Strengths and Difficulties Questionnaire (SDQ) [36]. Components of the sub-scale relate to whether respondents often had tantrums or hot tempers, were generally obedient, often fought with other children, often lied, or cheated and whether they stole from home, school or elsewhere. 'Somewhat True' was scored as 1, but the scoring of 'Not True' and 'Certainly True' varied with the item (either a score of 0 or 2). A composite conduct problem score was derived with higher scores indicating higher conduct problems.

\section{Exposure: residential air pollutant assessments}

Modelled annual mean $\mathrm{NO}_{2}$, Ozone $\left(\mathrm{O}_{3}\right), \mathrm{PM}_{10}$, and $\mathrm{PM}_{2.5}$ concentrations for London covering the years 2003-2004 and 2005-2006 were estimated, at a $20 \mathrm{~m} \times 20 \mathrm{~m}$ regular grid across the study area, using the King's College London (KCL) urban dispersion model [37]. The KCL urban model uses Atmospheric Dispersion Modelling System (ADMS) model v4 and road source model v2.3 (CERC19), hourly measured meteorological data, empirically derived NO- $\mathrm{NO}_{2}-\mathrm{O}_{3}$ and PM relationships, and emissions from the London Atmospheric Emissions Inventory (the LAEI;[38]) (the pollutant surface maps for London covering 2003 and 2006 are presented in Supplementary Figure 1). Each yearly model reflected a range of pollutant sources and emissions, including major and minor roads, with detailed information on vehicle stock, traffic flows, and speed on a link-by-link basis. Other sources within the model included large and small regulated industrial processes, boiler plants, domestic and commercial combustion sources, agriculture, rail, ships, airports, and pollution carried into the area by prevailing winds. The model performed well when evaluated against measurements, with low normalised mean bias and high spearman correlation coefficients $(\rho)$ between observed versus modelled concentrations: $\rho>0.9$ for $\mathrm{NOx}, \mathrm{O}_{3}, \mathrm{PM}_{10}$, and $\mathrm{PM}_{2.5}$ and $\rho>0.83$ for $\mathrm{NO}_{2}$ at both roadside and background locations. Further detail about the modelling procedure and model evaluation has been published previously and is available elsewhere [37, 39]. For linkage to the air pollution data, residential address at the time of survey was geocoded, locating the address to the nearest meter, and assigned annual air pollutant concentrations to the nearest $20 \mathrm{~m} \times 20 \mathrm{~m}$ grid point using bilinear interpolation.

Supplementary Figure 2 shows some small improvement in the modelled exposures to $\mathrm{NO}_{2}$ and $\mathrm{PM}_{2.5}$ between 11-13 and 14-16 years. Average ambient pollution concentrations during follow-up for $\mathrm{NO}_{2}$ were 41.6 (range 26.7 to 75.5$) \mu \mathrm{g} / \mathrm{m}^{3}$ and $\mathrm{PM}_{2.5} 20.1$ (14.4 to 24.4$) \mu \mathrm{g} / \mathrm{m}^{3}$.

\section{Effect modifiers: ethnicity and racism}

Ethnicity was self-reported, checked against reported parental ethnicity and grandparents' country of birth. Ethnic groups were categorised as follows; White UK, Black Caribbean, Black African, Indian, Pakistani/Bangladeshi, and Other (Mixed, Irish, Greek, Turkish, Kosovan, Albanian, Kurdish, Vietnamese, Singaporean, Pilipino, Japanese, Chinese, and other Asian).

Reported racism/discrimination ('no' or 'yes') was assessed at the baseline and follow-up surveys using the experiences of discrimination scale which includes questions on 'unfair treatment' on the grounds of race, skin colour, place of birth, and religion in various locations, e.g., school, work, on the street [40]. These are: 'Has anyone made you feel bad or hassled you because of your race, skin colour, or where you were born?' and 'Has anyone made you feel bad or hassled you because of your religion?'.

\section{Covariables}

A self-complete questionnaire was used to collect information on socio-demographics, parental mental health, and own lifestyle behaviours. Sex as well as parenting style, maternal mental health, adolescent health behaviours, family affluence, family type and labour market status, and neighbourhood deprivation were included in the models as timevariant covariables. Parenting style was captured using the eight-item Parental Bonding Instrument (PBI) which rates each item on a four-point Likert scale from which scores for parental care and parental control are derived [41]. Higher scores represent greater care and greater control. These scores were recoded into tertiles. Maternal mental health was measured by asking participants whether their mother/stepmother had mental health problems at survey time. Health behaviours were assessed by asking participants whether they had ever smoked or drank alcohol.

Family socio-economic circumstances were measured through a family affluence scale and categorised as $0-1$ (Least advantaged), 2 (Less advantaged), and $\geq 3$ (Least disadvantaged) [42]. Neighbourhood deprivation was measured by the income domain of the Index of Multiple Deprivation in 2004 and 2007 and categorised in quintiles. This area-based deprivation index measures the proportion of population that is living as low-income families at the Lower Super Output geographic level (LSOA). The higher the index score, the higher the area-based deprivation. 


\section{Statistical analysis}

To examine the association between air pollution and conduct problems in a sample of 4775 adolescents aged 11-16 years, and whether ethnicity and racism moderate this association, we fitted growth curve models. Preliminary analyses showed no significant clustering of conduct problems within schools or LSOAs.

Growth curve modelling allowed the estimation of individual conduct problem trajectories in adolescence, using age as an independent variable for time. Age (years) was centred at age 12 years (intercept). Analyses used two level models for repeated measures nested in adolescents and one slope for age to account for individual linear conduct problem trajectories.

Statistical analysis was conducted via STATA 16 v.1 (Stat Corp., College Station, Texas, USA). We considered as confounders: (i) factors related to both the exposure and the outcome in bivariable analyses $(P<0.20)$, (ii) factors that modified ( $>10 \%$ change in regression coefficient) the estimate of the exposure variable, or (iii) factors deemed relevant according to the scientific literature. High correlations were seen between all air pollution concentration estimates (all r's $>0.9$ ), and as such analyses in this paper focus on two pollutants for statistical parsimony and to minimise multiple testing: $\mathrm{PM}_{2.5}$ and $\mathrm{NO}_{2}$, which are known to cause adverse health effects and have been previously evaluated for association with mental health outcomes [43].

The following sequence of models was fitted to test the association between each ambient air pollutant and trajectories of conduct problems in adolescence, and the moderation of the association by gender, racism, and ethnicity. Model 1 contained each ambient air pollutant at the intercept (centred at age 12), age as a fixed effect and an interaction between each ambient air pollutant and the slope for age; Model 2 adjusted for all covariables to explore whether any association between each ambient air pollutant and conduct problems at age 12, as well as an association between ambient air pollution and the rate of change in conduct problems during adolescence was explained by their adjustment. Models 3 and 4 adjusted for interactions between each air pollutant, racism, and ethnicity. Model 5 considered the simultaneous interactions between each air pollutant and ethnicity. Statistical interactions were assessed using Wald tests. Models 2 and 5 are shown, since they are key models.

Multiple imputation by chained equations was used to deal with missing data in all analyses under the missing at random assumption. Sixty imputed datasets were created using regression switching. The imputation model included all exposures (residential air pollutants), effect modifiers (racism and ethnicity), covariables (sex, age in years at survey time, parenting style, maternal mental health, adolescent health behaviours, family affluence, family type, and labour market status neighbourhood deprivation), the outcome (conduct problems), and auxiliary variables (generational status and hyperactivity problems) to help predict missing data. Imputation models also included interaction terms between residential air pollutants, racism and ethnicity. The seed number was set at 03052020 . Results were combined using Rubin's rules [44]. Results from imputed data are reported.

\section{Results}

\section{Descriptive results}

Table 1 shows that Black Caribbean and Black African adolescents were exposed to higher levels of $\mathrm{PM}_{2.5}$ than their White British peers at baseline survey, while Black African adolescents were exposed to higher $\mathrm{PM}_{2.5}$ concentrations at follow-up. Black Caribbean and Black African adolescents were also exposed to higher $\mathrm{NO}_{2}$ concentrations than their White British peers at both baseline and follow-up surveys. Black Caribbean adolescents had higher conduct problems, whereas Indian adolescents had lower conduct problems than their White British counterparts. All ethnic minority groups reported more racism than White British adolescents (which increased with age). Ethnic minority adolescents were also more likely to live in materially less-advantaged households, and to live in more deprived neighbourhoods than White British participants.

\section{Ambient air pollution and trajectories of adolescent conduct problems}

Over time, higher $\mathrm{PM}_{2.5}$ and $\mathrm{NO}_{2}$ concentrations were associated with a flattened trajectory of conduct problems, while lower of $\mathrm{PM}_{2.5}$ and $\mathrm{NO}_{2}$ concentrations were associated with a decrease in conduct problems over time (Fig. 1). Table 2 shows that $\mathrm{PM}_{2.5}$ was associated with a greater rate of change of conduct problems during adolescence was $(\beta=0.06$ (95\% CI 0.03 to 0.08$) p<0.001)$ than $\mathrm{NO}_{2}(\beta=0.01$ (95\% CI 0.00 to 0.01$) p<0.001$ ), suggesting a stronger link between $\mathrm{PM}_{2.5}$ and change in conduct problems during adolescence. Adjustment for demographic characteristics, racism, psychosocial factors, health behaviours, maternal mental health problems, parenting style, individual, and area-level characteristics did not explain these associations.

\section{Effect modification by racism and ethnicity}

Model 3 showed that racism was associated with an amplification of the relationship betweenPM ${ }_{2.5}$ and adolescent trajectories of conduct problems over time (see Fig. 2), while Model 4 indicated a divergence of trajectories of 


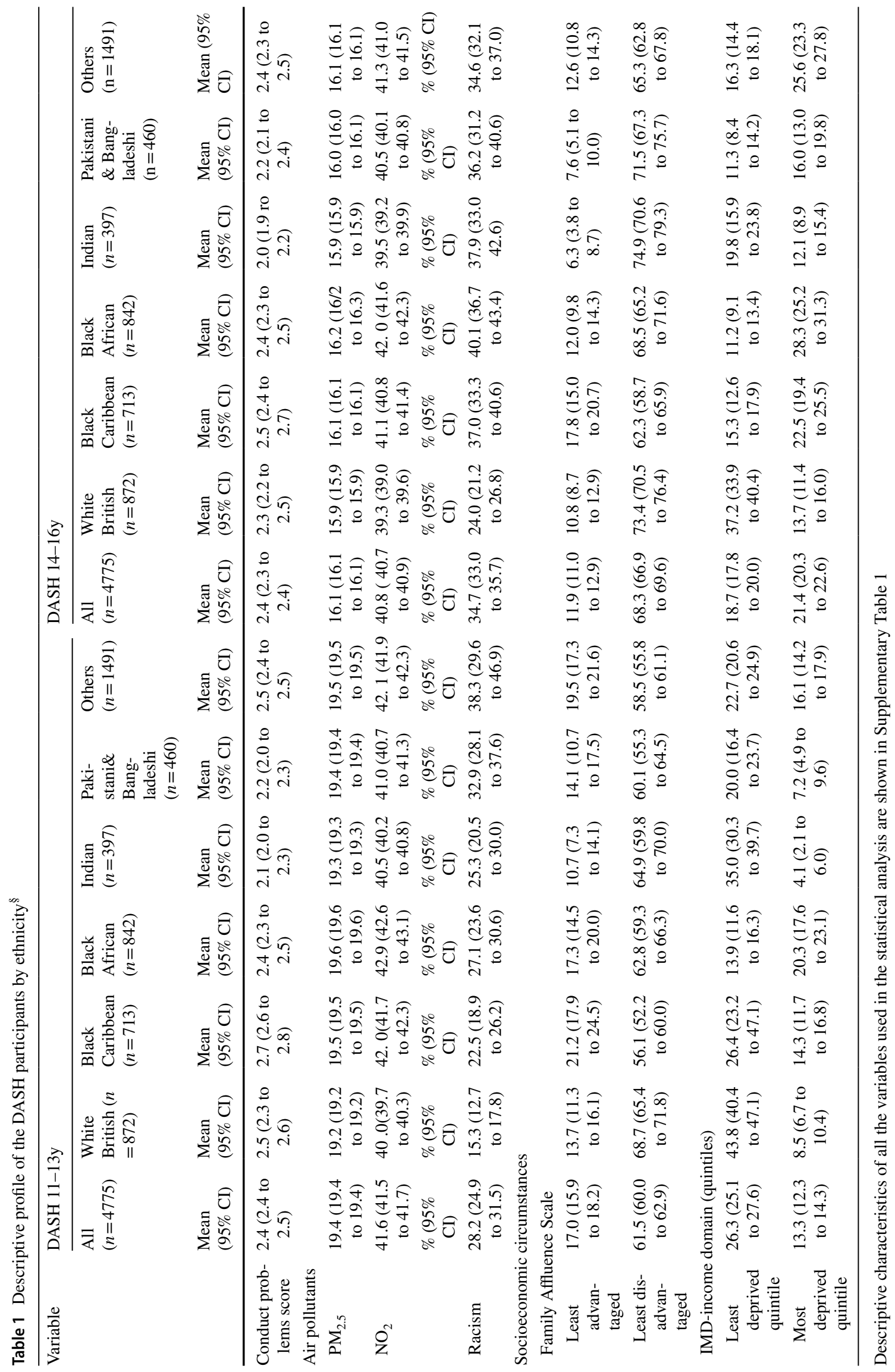


Table 2 Pooled and interactive effects of air pollution on trajectories of adolescent conduct problems

\begin{tabular}{|c|c|c|c|c|}
\hline & \multicolumn{2}{|c|}{ PM 2.5 and conduct problems } & \multicolumn{2}{|l|}{$\mathrm{NO}_{2}$ and conduct problems } \\
\hline & Model 2 & Model 5 & Model 2 & Model 5 \\
\hline & $\begin{array}{l}\text { Coefficient ( } 95 \% \text { confi- } \\
\text { dence interval) }\end{array}$ & $\begin{array}{l}\text { Coefficient ( } 95 \% \text { confi- } \\
\text { dence interval) }\end{array}$ & $\begin{array}{l}\text { Coefficient ( } 95 \% \text { confi- } \\
\text { dence interval) }\end{array}$ & $\begin{array}{l}\text { Coefficient (95\% confidence } \\
\text { interval) }\end{array}$ \\
\hline \multicolumn{5}{|l|}{ Fixed effects } \\
\hline Pollutant & $\begin{array}{l}-0.11(-0.17 \text { to } \\
-0.05)^{* * *}\end{array}$ & $\begin{array}{l}-0.09(-0.16 \text { to } \\
-0.02)^{* *}\end{array}$ & $-0.02(-0.03 \text { to } 0.00)^{*}$ & $-0.03(-0.05 \text { to } 0.01)^{*}$ \\
\hline Age & $\begin{array}{l}-1.22(-1.60 \text { to } \\
-0.84)^{* * *}\end{array}$ & $-1.16(-1.55$ to -0.78$)$ & $\begin{array}{l}-0.48(-0.69 \text { to } \\
-0.27)^{* * *}\end{array}$ & $\begin{array}{l}-0.48(-0.69 \text { to } \\
-0.27)^{* * *}\end{array}$ \\
\hline Pollutant*age & $0.06(0.03 \text { to } 0.08)^{* * *}$ & $0.06(0.04 \text { to } 0.08)^{* * *}$ & $0.01(0.00 \text { to } 0.01)^{* * *}$ & $0.01(0.00 \text { to } 0.01)^{* *}$ \\
\hline Female & $\begin{array}{c}-0.36 \\
* * *\end{array}$ & $\begin{array}{l}-0.92(-1.47 \text { to } \\
-0.25)^{* *}\end{array}$ & $\begin{array}{c}-0.36(-0.43 \text { to } \\
-0.28)^{* * *}\end{array}$ & $\begin{array}{l}-0.36(-0.43 \text { to } \\
-0.28)^{* * *}\end{array}$ \\
\hline Racism & $0.36(0.28 \text { to } 0.44)^{* * *}$ & $-0.61(-1.33$ to 0.10$)$ & $0.36(0.28$ to 0.43$) * * *$ & $0.44(-0.30$ to 1.18$)$ \\
\hline \multicolumn{5}{|l|}{ Ethnicity (Ref. White British) } \\
\hline Black Caribbean & $0.20(0.07 \text { to } 0.33)^{* *}$ & $0.65(-0.31$ to 1.60$)$ & $0.22(0.09 \text { to } 0.35)^{* *}$ & $0.00(-1.22$ to 1.24$)$ \\
\hline Black African & $0.12(-0.01$ to 0.25$)$ & $1.34(0.41 \text { to } 2.26)^{* *}$ & 0.13 (0.00 to 0.26$)$ & $-0.57(-1.71$ to 0.56$)$ \\
\hline Indian & $-0.13(-0.29$ to 0.02$)$ & $0.59(-0.51$ to 1.71$)$ & $-0.15(-0.31$ to 0.01$)$ & $-0.23(-1.94$ to 1.48$)$ \\
\hline Pakistani \& Bangladeshi & $-0.05(-0.20$ to 0.10$)$ & $1.81(0.71 \text { to } 2.92)^{* *}$ & $-0.08(-0.23$ to 0.07$)$ & $0.47(-1.17$ to 2.12$)$ \\
\hline Others & $0.04(-0.07$ to 0.15$)$ & $1.24(0.41 \text { to } 2.08)^{* *}$ & $0.04(-0.07$ to 0.15$)$ & $-0.24(-1.27$ to 0.79$)$ \\
\hline \multicolumn{5}{|l|}{ Moderation } \\
\hline Pollutant*racism & & $0.05(0.01 \text { to } 0.10)^{* *}$ & & $0.00(-0.02$ to 0.02$)$ \\
\hline \multicolumn{5}{|l|}{$\begin{array}{l}\text { Pollutant*ethnicity (Ref. } \\
\text { White British) }\end{array}$} \\
\hline Black Caribbean & & $-0.02(-0.08$ to 0.03$)$ & & $0.00(-0.02$ to 0.03$)$ \\
\hline Black African & & $\begin{array}{l}-0.07(-0.12 \text { to } \\
-0.02)^{* *}\end{array}$ & & $0.02(-0.025$ to 0.03$)$ \\
\hline Indian & & $-0.04(-0.10$ to 0.02$)$ & & $0.00(-0.04$ to 0.04$)$ \\
\hline Pakistani \& Bangladeshi & & $\begin{array}{l}-0.11(-0.17 \text { to } \\
-0.04)^{* *}\end{array}$ & & $-0.01(-0.05$ to 0.03$)$ \\
\hline Others & & $\begin{array}{l}-0.07(-0.12 \text { to } \\
-0.02)^{* *}\end{array}$ & & $0.01(-0.02$ to 0.032$)$ \\
\hline \multicolumn{5}{|l|}{ Random effects } \\
\hline $\begin{array}{l}\text { Level } 2 \text { (Between-child } \\
\text { intercept variance) }\end{array}$ & $0.89(0.85$ to 0.94$)$ & $0.89(0.85$ to 0.93$)$ & $0.89(0.85$ to 0.93$)$ & $0.89(0.85$ to 0.93$)$ \\
\hline Level 1 (occasion) & $1.25(1.22$ to 1.28$)$ & $1.25(1.22$ to 1.29$)$ & $1.26(1.23$ to 1.28$)$ & $1.26(1.23$ to 1.28$)$ \\
\hline
\end{tabular}

All statistical models are shown in supplementary Tables 2 and 3

* $\mathrm{p}<0.05, * * \mathrm{p}<0.01, * * * \mathrm{p}<0.001$

Model 2-Ambient air pollutant, age, ambient air pollutant * age, racism, sex, ethnicity, maternal mental health problems, parental care, parental control, cigarette smoking, alcohol, family affluence and IMD (income domain)

Model 5-Model 2+ambient air pollutant *racism + ambient air pollutant * ethnicity

adolescent conduct problems associated to higher levels of $\mathrm{PM}_{2.5}$ between ethnic minority groups (see Fig. 3), with White British and Black Caribbean adolescents experiencing an increase in conduct problems over time.

Adjustment for demographic characteristics, psychosocial factors, health behaviours, individual- and area-level characteristics, as well as mutual adjustment for statistical interactions with racism, and ethnicity (Model 5) did not affect the interpretation of the findings. No significant interactions were observed for $\mathrm{NO}_{2}$ (see Table 2 and Supplementary Table 3).

\section{Sensitivity analysis}

Analyses of non-imputed data did not affect the pattern and the significance of findings shown in Model 2 (association between $\mathrm{PM}_{2.5}$ and conduct problems). The pattern of findings was maintained for the interactions between 
Fig. 2 Predicted conduct problem trajectories by self-reported racism and $\mathrm{PM}_{2.5}$ concentration level (Model 5). Predictions are plotted as below average $\left(\mathrm{PM}_{2.5}<17.7 \mathrm{mg} / \mathrm{m}^{3}\right)$ and above average $\left(\mathrm{PM}_{2.5}>17.7 \mathrm{mg} / \mathrm{m}^{3}\right)$ for DASH participants who experienced racism and those who were not. Predictions were restricted between ages 12 and 16 years where measures of $\mathrm{PM}_{2.5}$ and conduct scores were more robust

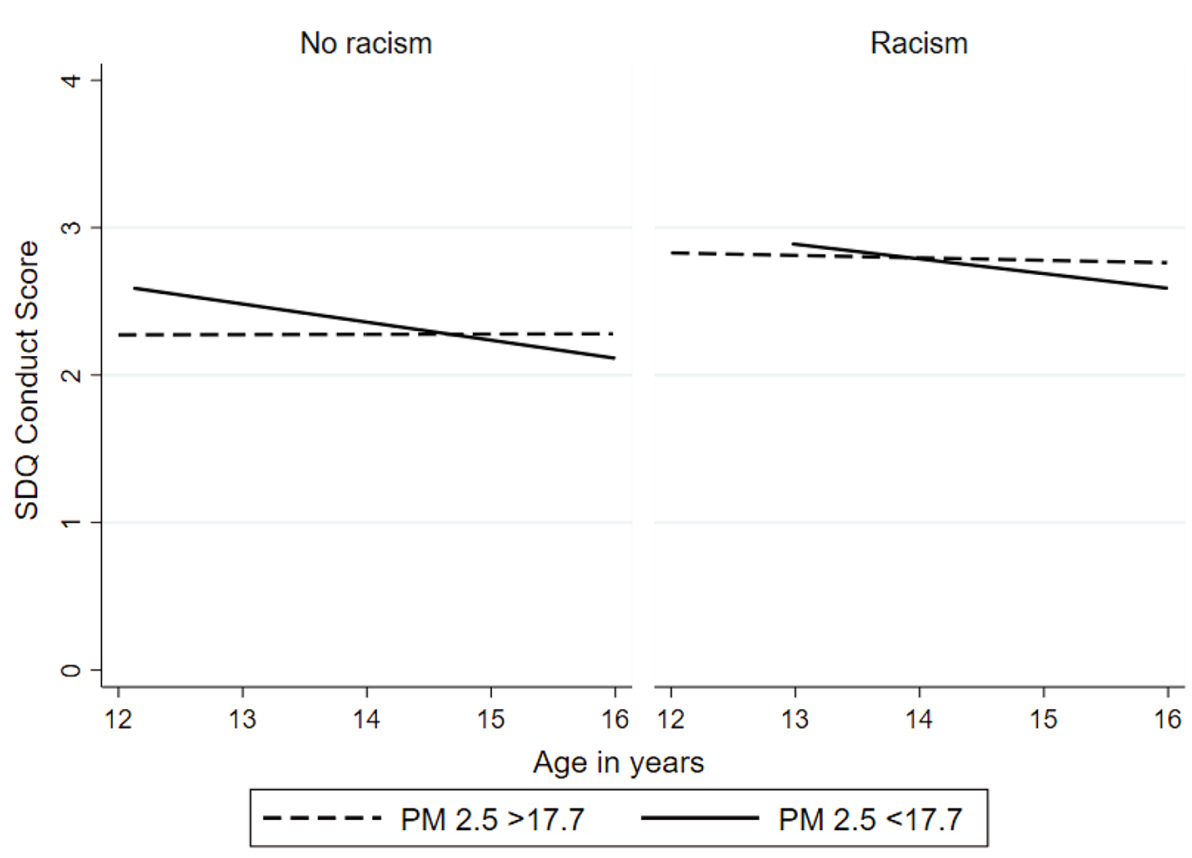

PM $2.5<17.7$

PM $2.5>17.7$

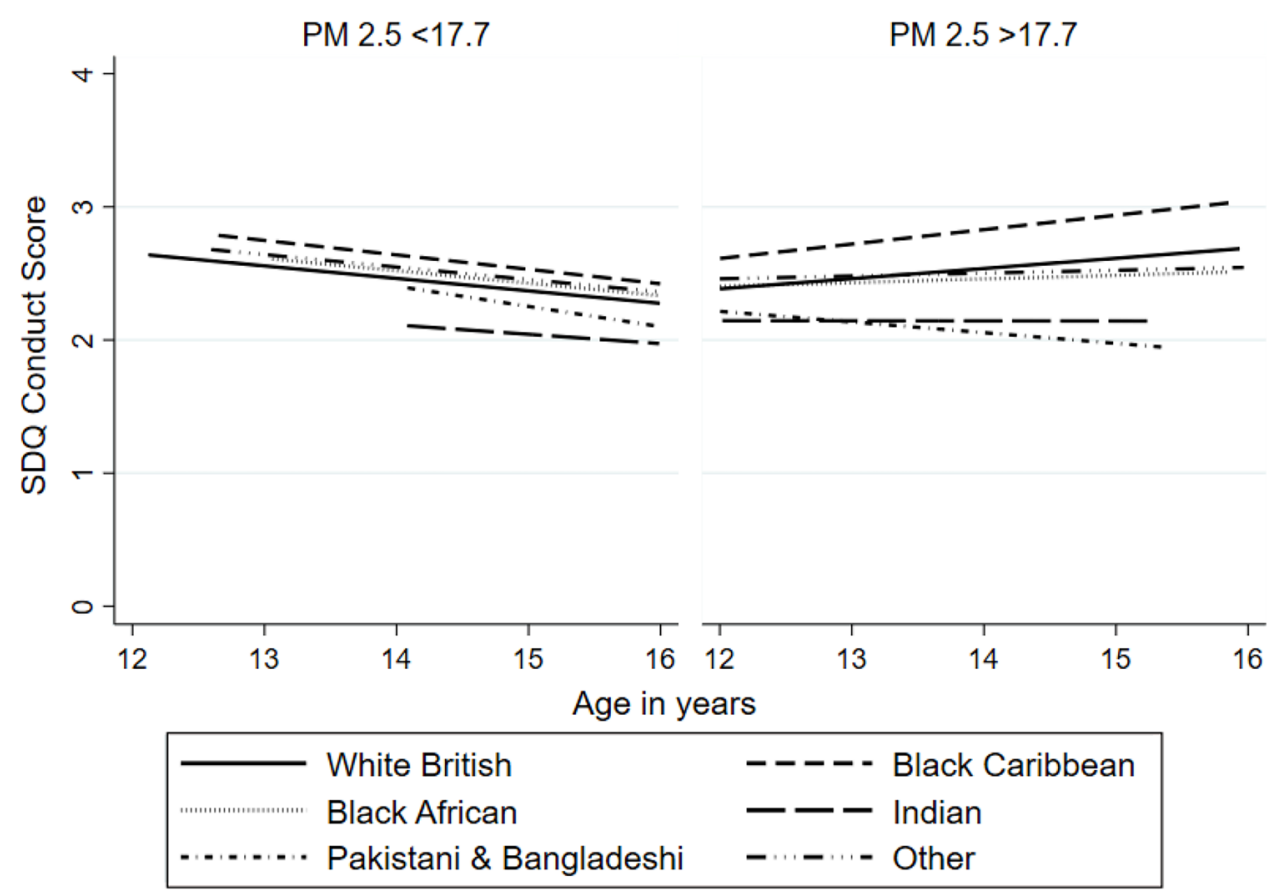

Fig. 3 Predicted conduct problem trajectories by ethnicity and $\mathrm{PM}_{2.5}$ concentration level (Model 5). Predictions are plotted as below average $\left(\mathrm{PM}_{2.5}<17.7 \mathrm{mg} / \mathrm{m}^{3}\right)$ and above average $\left(\mathrm{PM}_{2.5}>17.7 \mathrm{mg} / \mathrm{m}^{3}\right)$ $\mathrm{PM}_{2.5}$ concentration level for each ethnic group. Predictions were restricted between ages 12 and 16 years where measures of $\mathrm{PM}_{2.5}$ and conduct scores were more robust
$\mathrm{PM}_{2.5}$, racism, and ethnicity (Model 5), but significance was lost (see Supplementary Table 4).

Further sensitivity analyses explored whether there was evidence of a modifying of sex on the interplay between $\mathrm{PM}_{2.5}$ or $\mathrm{NO}_{2}$, racism, and ethnicity on adolescent trajectories of conduct problems. No evidence was provided for effect modification.

We repeated analyses using a two-pollutant model $\left(\mathrm{PM}_{2.5}\right.$ and $\mathrm{NO}_{2}$ ) to examine co-pollutant confounding in Model 5 (see Supplementary Table 5). The associations arising from
$\mathrm{PM}_{2.5}$ remained relatively unchanged when simultaneously modelled with $\mathrm{NO}_{2}$, while the associations arising from $\mathrm{NO}_{2}$ were null when simultaneously modelled with $\mathrm{PM}_{2.5}$. This finding suggests that associations arising from $\mathrm{PM}_{2.5}$ were not driven by $\mathrm{NO}_{2}$ or another factor correlated with $\mathrm{NO}_{2}$, while associations arising from $\mathrm{NO}_{2}$ were confounded by $\mathrm{PM}_{2.5}$.

Finally, we considered potential associations between racism, exposure to higher $\mathrm{PM}_{2.5}$ concentrations, and adolescents' attention deficit/hyperactivity problems. No 
interaction was observed (results not shown), highlighting the possible exacerbating role of racism only on adolescents' conduct problems who are exposed to higher $\mathrm{PM}_{2.5}$ concentrations.

\section{Discussion}

\section{Statement of principal findings}

Using data from one of the largest known and most diverse longitudinal multi-ethnic cohort studies of adolescents in the UK, we found that exposure to higher $\mathrm{PM}_{2.5}$ and $\mathrm{NO}_{2}$ concentrations was associated with a flattened trajectory of conduct problems, while exposure to lower $\mathrm{PM}_{2.5}$ and $\mathrm{NO}_{2}$ concentrations was associated with a decrease in conduct problems. Among adolescents who were exposed to higher $\mathrm{PM}_{2.5}$ concentrations, racism was associated with an increase in conduct problems, but not with attention deficit/ hyperactivity problems. Finally, exposure to higher $\mathrm{PM}_{2.5}$ concentrations was associated with an exacerbation of ethnic differences in conduct problems during adolescence for White and Black Caribbean participants.

\section{Strengths and weaknesses of the study}

DASH has high retention rates due to enormous community support. The cohort's composition is unique with large numbers from the main UK ethnic groups. Weaknesses include the lack of data before age 11 years, the lack of information on individual-level exposure to ambient air pollution, potential residual environmental confounding such as lack of exposure to green space or data to inform the mechanisms linking air pollution and conduct problems in adolescence such as noise pollution, sleep or inflammatory biomarkers, and lack of statistical power to explore three-way interactions between time, air pollutants, and racism or ethnicity.

\section{Interpretation}

The association between long-term $\mathrm{PM}_{2.5}$ exposures with conduct problems aligns with previous evidence from animal studies, where phenotypes associated with impulsivity (a behaviour characterised by little or no reflection, or consideration of the consequences) were more prevalent in mice with early life exposures to concentrated ambient ultrafine particles [45]. Although mechanisms of these effects are not fully elucidated, such neurobehavioral effects may be mediated by particle-induced alteration of the mesocorticolimbic dopamine system associated with impulsive-antisocial behaviour [45].

There is a difficulty in comparing this study's findings with those from other human studies. First, there is a paucity of follow-up studies exploring the association between air pollutants and mental health in adolescents. Second, a few studies exist with a focus on air pollution and conduct problems. Third, different scales and criteria have been used to measure conduct problems in adolescence.

The association between $\mathrm{PM}_{2.5}$ and higher conduct problems in adolescence corroborates the findings of a US longitudinal study in South California following 682 participants from age 9 to age 18 years [20]. This study reported that interquartile increases in $\mathrm{PM}_{2.5}$ by $3.12-5.18 \mu \mathrm{g} / \mathrm{m}^{3}$ were associated with higher conduct problems at age 9 years using the Child Behaviour Checklist (CBCL), but not with the rate of change of conduct problems. A cross-sectional study of 174 participants aged 7-14 years in Boston, US found that that traffic-related black carbon was associated with increased impulsivity using the Conner's Continuous Performance Test, with the effects being greater for boys [46]. Conversely, a cross-sectional study of 284 participants in London reported no association between higher concentrations of $\mathrm{PM}_{2.5}$ and $\mathrm{NO}_{2}$ at age 12 and higher conduct problems at age 12 and 6 years later at age 18 using DSM-IV criteria [17]. Finally, a meta-analysis of 13,182 participants aged 7-11 years in five European countries (The Netherlands, Germany, Poland, France, and Spain) and from 8 birth cohort studies did not find evidence of associations between exposure to prenatal and postnatal increases in $\mathrm{NO}_{2}$ and $\mathrm{PM}_{2.5}$ concentrations with a greater likelihood of probable clinical conduct problems using the CBCL and the SDQ [47].

Our study provides novel insights into the development of adolescent conduct problems as well as ethnic differences in the development of conduct problems in response to exposure to $\mathrm{PM}_{2.5}$ concentrations. They also further our understanding of the synergies between $\mathrm{PM}_{2.5}$ and racism in the development conduct problems during the sensitive period of adolescence [48]. Some argue that an emotional mechanism, in which anger and belief in the legitimacy of violence act as indirect links, connects racism and conduct problems [49]. Since racism may elicit these attitudes, adolescents may become more likely to affiliate with peers who have similar outlooks. Therefore, social selection effects such as these may lead to social influence effects, which may further influence conduct problems in adolescence [50,51]. There is also increasing evidence highlighting that psychological stress may enhance a child's vulnerability to certain chemical exposures, signalling the importance of studying interactions of social-chemical stressors [52]. In our study, the $\mathrm{PM}_{2.5}$-conduct problems' association was stronger in adolescents who reported racism. However, the neurobiological mechanisms underlying the amplification of adverse neurobehavioral effects of airborne particles by self-reported racism are unclear. It is possible that adolescents who endure ongoing racism are in a prolonged state of toxic stress [53]. 
Growing evidence suggests that chronic stress may act upon one or more of the same critical physiological pathways as air pollutants, including oxidative stress, inflammation, and autonomic disruption [52].

\section{Conclusions}

Our study contributes new evidence on the association between $\mathrm{PM}_{2.5}$ and conduct problems during the sensitive period of adolescence, and on the interplay between ambient $\mathrm{PM}_{2.5}$, racism, and ethnicity in the development of adolescent conduct problems.

\section{Data sharing statement}

The DASH data are available to researchers via a data request to the MRC Social and Public Health Science Unit. Applications and the data sharing policy for DASH can be found at http://dash.sphsu.mrc.ac.uk/DASH_dsp_v1_Novem ber-2012_draft.pdf. It reflects the MRC guidance on data sharing with the aim of making the data as widely and freely available as possible while safeguarding the privacy of participants, protecting confidential data, and maintaining the reputation of the study. All potential collaborators work with a link person, an experienced DASH researcher-to support their access to and analysis of the data. The variable-level metadata is available from the study team and via the MRC Data Gateway.

Supplementary Information The online version contains supplementary material available at https://doi.org/10.1007/s00127-021-02097-7.

Acknowledgements We acknowledge the invaluable support of participants and their parents, the Participant Advisory Group, schools, civic leaders, local GP surgeries and community pharmacies, the Clinical Research Centre at Queen Mary University of London, the Clinical Research Facility at University College Hospital, the survey assistants and nurses involved in DASH data collection. IM, FK, and SDB are supported by the National Institute for Health Research (NIHR) Health Protection Research Unit in Environmental Exposures and Health, a partnership between Public Health England and Imperial College London. The views expressed are those of the author(s) and not necessarily those of the NIHR, Public Health England or the Department of Health and Social Care.

Author contributions $\mathrm{AK}$ and $\mathrm{SH}$ contributed equally to this paper. $\mathrm{AK}$ produced the first draft of the manuscript. SH is the Principal Investigator of DASH, conceptualised the study, implementation, manuscript discussion and critical revision.SH, MM, EE, and JKC oversaw the conduct of the DASH study, recruitment of participants and collection of data. AK, YL, ST, SH, and CE conducted the quality assurance of the data and statistical analyses. IM, FK, SDB and DD provided expertise in the measurement of air pollution, while PD provided expertise in the interpretation of the findings. All authors contributed to study design and analyses and contributed to the development of the manuscript and approved the final version.

Funding The study was funded by the Medical Research Council (10. 13039/N4 501100000265, MC_U130015185/MC_UU_12017/1/ MC_ UU_12017/13) North Central London Consortium and the Primary Care Research Network.

\section{Declarations}

Ethics approval The Multicentre Research Ethics Committee (MREC) and NHS Local Research Ethics Committees.

Patient consent Obtained.

Conflict of interest None declared.

Open Access This article is licensed under a Creative Commons Attribution 4.0 International License, which permits use, sharing, adaptation, distribution and reproduction in any medium or format, as long as you give appropriate credit to the original author(s) and the source, provide a link to the Creative Commons licence, and indicate if changes were made. The images or other third party material in this article are included in the article's Creative Commons licence, unless indicated otherwise in a credit line to the material. If material is not included in the article's Creative Commons licence and your intended use is not permitted by statutory regulation or exceeds the permitted use, you will need to obtain permission directly from the copyright holder. To view a copy of this licence, visit http://creativecommons.org/licenses/by/4.0/.

\section{References}

1. American Psychiatric Association. Diagnostic and statistical manual of mental disorders, Fifth Edition2013.

2. Flouri E, Ruddy A, Midouhas E (2017) Maternal depression and trajectories of child internalizing and externalizing problems: the roles of child decision making and working memory. Psychol Med 47(6): 1138-1148

3. Bevilacqua L, Hale D, Barker ED, Viner R (2018) Conduct problems trajectories and psychosocial outcomes: a systematic review and meta-analysis. Eur Child Adoles Psy 27(10):1239-1260

4. Gutman LM, Joshi H, Schoon I (2019) Developmental trajectories of conduct problems and cumulative risk from early childhood to adolescence. J Youth Adolescence 48(2):181-198

5. Flouri E, Papachristou E, Midouhas E, Ploubidis GB, Lewis G, Joshi H (2019) Developmental cascades of internalising symptoms, externalising problems and cognitive ability from early childhood to middle adolescence. Eur Psychiatry 57:61-69

6. McLeod J, Kaiser K (2004) Childhood emotional and behavioral problems and educational attainment. Am Sociol Rev 69:636-658

7. Moffitt TE (1993) Adolescence-limited and life-course-persistent antisocial behavior: a developmental taxonomy. Psychol Rev 100(4):674-701

8. Loeber R, Wung P, Keenan K, Giroux B, Southamer-Loeber MM, van Kammen W (1993) Developmental pathways in disruptive child behavior. Dev Psychopathol 5(1-2):101-132

9. Scott S, Knapp M, Henderson J, Maughan B (2001) Financial cost of social exclusion: follow up study of antisocial children into adulthood. BMJ 373:191 
10. Maughan B, Stafford M, Shah I, Kuh D (2014) Adolescent conduct problems and premature mortality: follow-up to age 65 years in a national birth cohort. Psychol Med 44(5):1077-1086

11. Colman I, Murray J, Abbott RA, Maughan B, Kuh D, Croudace TJ et al (2009) Outcomes of conduct problems in adolescence: 40 year follow-up of national cohort. BMJ 338:a2981

12. Priest N, Paradies Y, Trenerry B, Truong M, Karlsen S, Kelly Y (2013) A systematic review of studies examining the relationship between reported racism and health and wellbeing for children and young people. Soc Sci Med 95:115-127

13. Flouri E, Mavroveli S, Midouhas E (2013) Residential mobility, neighbourhood deprivation and children's behaviour in the UK. Health Place 20:25-31

14. Brody GH, Chen YF, Murry VM, Ge X, Simons RL, Gibbons FX et al (2006) Perceived discrimination and the adjustment of African American youths: a five-year longitudinal analysis with contextual moderation effects. Child Dev 77(5):1170-1189

15. Maughan B, McCarthy G (1997) Childhood adversities and psychosocial disorders. Br Med Bull 53(1):156-169

16. Newbury JB, Arseneault L, Beevers S, Kitwiroon N, Roberts S, Pariante CM et al (2019) Association of air pollution exposure with psychotic experiences during adolescence. JAMA Psychiat 76(6):614-623

17. Roberts S, Arseneault L, Barratt B, Beevers S, Danese A, Odgers CL et al (2019) Exploration of NO2 and PM2.5 air pollution and mental health problems using high-resolution data in Londonbased children from a UK longitudinal cohort study. Psychiatry Res 272:8-17

18. Mueller MAE, Flouri E, Kokosi T (2019) The role of the physical environment in adolescent mental health. Health Place 58:102153

19. Forns J, Dadvand P, Foraster M, Alvarez-Pedrerol M, Rivas L, López-Vicente $\mathrm{M}$ et al (2016) Traffic-related air pollution, noise at school, and behavioral problems in Barcelona schoolchildren: a cross-sectional study. Environ Health Perspect 124(4):529-535

20. Younan D, Tuvblad C, Franklin M, Lurmann F, Li L, Wu J et al (2018) Longitudinal analysis of particulate air pollutants and adolescent delinquent behavior in Southern California. J Abnorm Child Psychol 46(6):1283-1293

21. Block ML, Calderon-Garciduenas L (2009) Air pollution: mechanisms of neuroinflammation and CNS disease. Trends Neurosci 32(9):506-516

22. Genc S, Zadeoglulari Z, Fuss SH, Genc K (2012) The adverse effects of air pollution on the nervous system. J Toxicol 2012:782462

23. Mudway IS, Kelly FJ, Holgate ST (2020) Oxidative stress in air pollution research. Free Radic Biol Med 151:2-6

24. Cameron B, Landreth GE (2010) Inflammation, microglia, and Alzheimer's disease. Neurobiol Dis 37(3):503-509

25. Pun PB, Lu J, Moochhala S (2009) Involvement of ROS in BBB dysfunction. Free Radic Res 43(4):348-364

26. Quinlan EB, Cattrell A, Jia T, Artiges E, Banaschewski T, Barker $\mathrm{G}$ et al (2017) Psychosocial stress and brain function in adolescent psychopathology. Am J Psychiatry 174(8):785-794

27. Goodman A, Patel P, Leon DA (2008) Why do British Indian children have an apparent mental health advantage? J Child Psychol Psychiatry 51(10):1171-1183

28. Klineberg E, Clark C, Bhui KS, Haines MM, Viner RM, Head J et al (2006) Social support, ethnicity and mental health in adolescents. Soc Psychiatry Psychiatr Epidemiol 41(9):755-760

29. Maynard MJ, Harding S, Minnis H (2007) Psychological wellbeing in Black Caribbean, Black African, and White adolescents in the UK Medical Research Council DASH study. Soc Psychiatry Psychiatr Epidemiol 42(9):759-769

30. Maynard MJ, Harding S (2010) Perceived parenting and psychological well-being in UK ethnic minority adolescents. Child Care Health Dev 36(5):630-638
31. Aether. Air pollution exposure in London: impact of the London environment strategy - a report for the Greater London Authority. 2019.

32. Guite HF, Clark C, Ackrill G (2006) The impact of the physical and urban environment on mental well-being. Public Health 120(12):1117-1126

33. Leventhal T, Brooks-Gunn J. The neighbourhoods they live in: the effects of neighbourhood residence on child and adolescent outcomes. Psychol Bull 2000;126:309-37.

34. Statistics OfN. People living in deprived neighbourhoods. 2020.

35. Harding S, Whitrow M, Maynard MJ, Teyhan A (2007) Cohort profile: The DASH (Determinants of Adolescent Social wellbeing and Health) Study, an ethnically diverse cohort. Int J Epidemiol 36(3):512-517

36. Goodman A, Goodman R (2011) Population mean scores predict child mental disorder rates: validating SDQ prevalence estimators in Britain. J Child Psychol Psychiatry 52(1):100-108

37. Beevers SD, Kitwiroon N, Williams ML, Kelly FJ, Ross Anderson H, Carslaw DC (2013) Air pollution dispersion models for human exposure predictions in London. J Expo Sci Environ Epidemiol 23(6):647-653

38. Greater London Authority. London Atmospheric Emissions Inventory (LAEI) 2010 London; 2010. https://data.london.gov.uk/datas et/london-atmospheric-emissions-inventory-2010.

39. Beevers SD DD. Traffic project supplementary files. Air pollution model. KCL urban model description, evaluation and outputs; 2015. https://www.kcl.ac.uk/lsm/research/divisions/aes/resea $\mathrm{rch} / \mathrm{ERG} /$ research-projects/traffic/TRAFFIC-SM-Air-pollutionModel.pdf.

40. Krieger N, Sidney S (1996) Racial discrimination and blood pressure: the CARDIA Study of young black and white adults. Am J Public Health 86(10):1370-1378

41. Mackinnon AJ, Henderson AS, Scott R, Duncan-Jones P (1989) The Parental Bonding Instrument (PBI): an epidemiological study in a general population sample. Psychol Med 19(4):1023-1034

42. William B, Torsheim T, Currie C, Zambon A (2006) The family affluence scale as a measure of National Wealth: validation of an adolescent self-report measure. Soc Indic Res 78:473-487

43. Costa S, Ferreira J, Silveira C, Costa C, Lopes D, Relvas H et al (2014) Integrating health on air quality assessment-review report on health risks of two major European outdoor air pollutants: PM and $\mathrm{NO}_{2}$. J Toxicol Environ Health B Crit Rev 17(6):307-340

44. Marshall A, Altman DG, Holder RL, Royston P (2009) Combining estimates of interest in prognostic modelling studies after multiple imputation: current practice and guidelines. BMC Med Res Methodol 9:57

45. Allen JL, Liu X, Weston D, Prince L, Oberdorster G, Finkelstein JN et al (2014) Developmental exposure to concentrated ambient ultrafine particulate matter air pollution in mice results in persistent and sex-dependent behavioral neurotoxicity and glial activation. Toxicol Sci 140(1):160-178

46. Yueh-Hsiu MC, Bellinger DC, Coull BA, Andersonm S, Barber B, Wright RO et al (2013) Associations between traffic-related black carbon exposure and attention in a prospective birth cohort of urban children. Environ Health Perspect 121(7):859-864

47. Jorcano A, Lubczynska MJ, Pierotti L, Altug H, Ballester F, Cesaroni $\mathrm{G}$ et al (2019) Prenatal and postnatal exposure to air pollution and emotional and aggressive symptoms in children from 8 European birth cohorts. Environ Int 131:104927

48. Viner RM, Ross D, Hardy R, Kuh D, Power C, Johnson A et al (2015) Life course epidemiology: recognising the importance of adolescence. J Epidemiol Community Health 69(8):719-720

49. Simons RL, Chen Y-E, Stewart EA, Brody GH (2003) Incidents of discrimination and risk for delinquency: a longitudinal test of strain theory with an African American sample. Justice Q $20: 827-854$ 
50. Menard S, Elliott DS (1994) Delinquent bonding, moral beliefs, and illegal behavior: a three-wave panel model. Justice Q 11:173-188

51. Thornberry TP, Krohn MD (1997) Peers, drug use, and delinquency. In: Stoff DM, Breiling J (eds) Handbook of antisocial behaviour. Wiley, New York, pp 218-233

52. Cooney CM (2011) Stress-pollution interactions: an emerging issue in children's health research. Environ Health Perspect 119(10):A431-A435
53. McEwen BS, Tucker P (2011) Critical biological pathways for chronic psychosocial stress and research opportunities to advance the consideration of stress in chemical risk assessment. Am J Public Health 101(Suppl 1):S131-S139 